\title{
Investigation into Phase Transformations and Structural and Luminescent Properties of Multiphase Coatings and Aluminum Oxide Nanopowder Prepared by Evaporation with a Pulsed Electron Beam
}

\author{
S. Yu. Sokovnin ${ }^{a, b}$ and V. G. Il'ves ${ }^{a}$ \\ ${ }^{a}$ Institute of Electrophysics, Ural Branch, Russian Academy of Sciences, ul. Amudsena 106, Yekaterinburg, 620016 Russia \\ ${ }^{b}$ Yeltsin Ural Federal University, ul. Mira 19, Yekaterinburg, 620002 Russia \\ e-mail: sokovnin@iep.uran.ru \\ Received May 14, 2012; accepted November 12, 2012
}

\begin{abstract}
Multiphase nanopowder and amorphous/amorphous-nanocrystal coatings on the basis of $\mathrm{Al}_{2} \mathrm{O}_{3}$ have been produced on a glass substrate by the method of pulsed electron-beam evaporation in vacuum. Their characteristics are studied by XRD, BET, pulsed cathodoluminescence, and differential scanning calorimetry (DSC)/thermogravimetric analysis. The effect of the deposition time of nanoparticles (NPs) on the phase composition of coatings and nanopowders is established. The correlation of luminescent properties with the phase composition of coatings and nanopowders is detected. Amorphous-nanocrystal coatings and nanopowders containing an $\mathrm{Al}_{2} \mathrm{O}_{3} \gamma$ phase with a defective cubic spinel structure are promising materials for the dosimetry of different types of ionizing radiation.
\end{abstract}

DOI: $10.1134 / \mathrm{S} 1995078013020171$

\section{INTRODUCTION}

The unique magneto-luminescent properties of aluminum oxide nanopowders (NPWs) [1, 2] and thin films [3] indicate their potential for application in optoelectronics, spintronics, dosimetry, catalysis, and other areas of science and technology. A large number of studies on the preparation of amorphous and amorphous-nanocrystal (A-NC) films [4, 5], coatings $[6,7]$, and submicron- and nanopowders $[8,9]$ on the basis of $\mathrm{Al}_{2} \mathrm{O}_{3}$ using various high-temperature methods, pulsed laser deposition (PLD) [10, 11], evaporation by a continuous and pulsed electron beam $[2,12]$, various modifications of magnetron sputtering $[6,7]$, plasma chemical technologies [13, 14], detonation synthesis $[15,16]$, and others are known. The results of these studies show that the routes of formation and phase transformation of the $\mathrm{Al}_{2} \mathrm{O}_{3}$-based nanomaterials upon further annealing are characterized by exceptional diversity and depend on manifold factors: the initial precursor, the method of synthesis used and its conditions, the temperature and crystallographic orientation of the substrate [17, 18], etc. An amorphous phase, which is further transformed into the $\gamma$-phase $\mathrm{Al}_{2} \mathrm{O}_{3}$ upon annealing, is most often formed upon the deposition of thin films onto relatively cold substrates $\left(25-250^{\circ} \mathrm{C}\right)[19-21]$ using evaporation by the electron beam. The $\gamma$ phase in turn can remain thermally stable up to high temperatures of approximately $1000-1100^{\circ} \mathrm{C}[4]$.
A $\alpha$ phase of anion-defective corundum ceramic is widely used as a thermoluminescence detector of various types of ionizing radiation [22]. The potential of using thin films with a thickness less than $3 \mu \mathrm{m}$ [23, 24], micron powders and granules [25] for the dosimetry of beta particles, and ultraviolet and gamma radiation is mentioned only in few publications. There are very few studies devoted to investigating thermoluminescent and dosimetric characteristics of amorphous films and coatings consisting of various polymorphic phases of $\mathrm{Al}_{2} \mathrm{O}_{3}$, in particular coatings containing nanocrystals (NC) of the $\mathrm{Al}_{2} \mathrm{O}_{3} \gamma$ phase with a defective spinel structure in the amorphous matrix.

The aim of this work is to prepare A-NC coatings and NPW on the basis of $\mathrm{Al}_{2} \mathrm{O}_{3}$ through the evaporation of an $\alpha-\mathrm{Al}_{2} \mathrm{O}_{3}$ ceramic target using a pulsed electron beam in vacuum and the investigation of their structural and luminescent properties, thermal stability, and the routes of their phase transformations upon heating to $1400^{\circ} \mathrm{C}$.

\section{EXPERIMENTAL}

Coatings and NPWs were prepared by the evaporation of the ceramic target in vacuum (residual pressure $4 \mathrm{~Pa}$ ) using a pulsed electron beam on a NANOBIM-2 instrument [26]. The electron energy was $40 \mathrm{keV}$, the pulse energy was $1.8 \mathrm{~J}$, the pulse duration was $100 \mu \mathrm{s}$, and the pulse frequency was $100-200 \mathrm{~Hz}$. Coatings and NPWs were obtained in identical experimental 


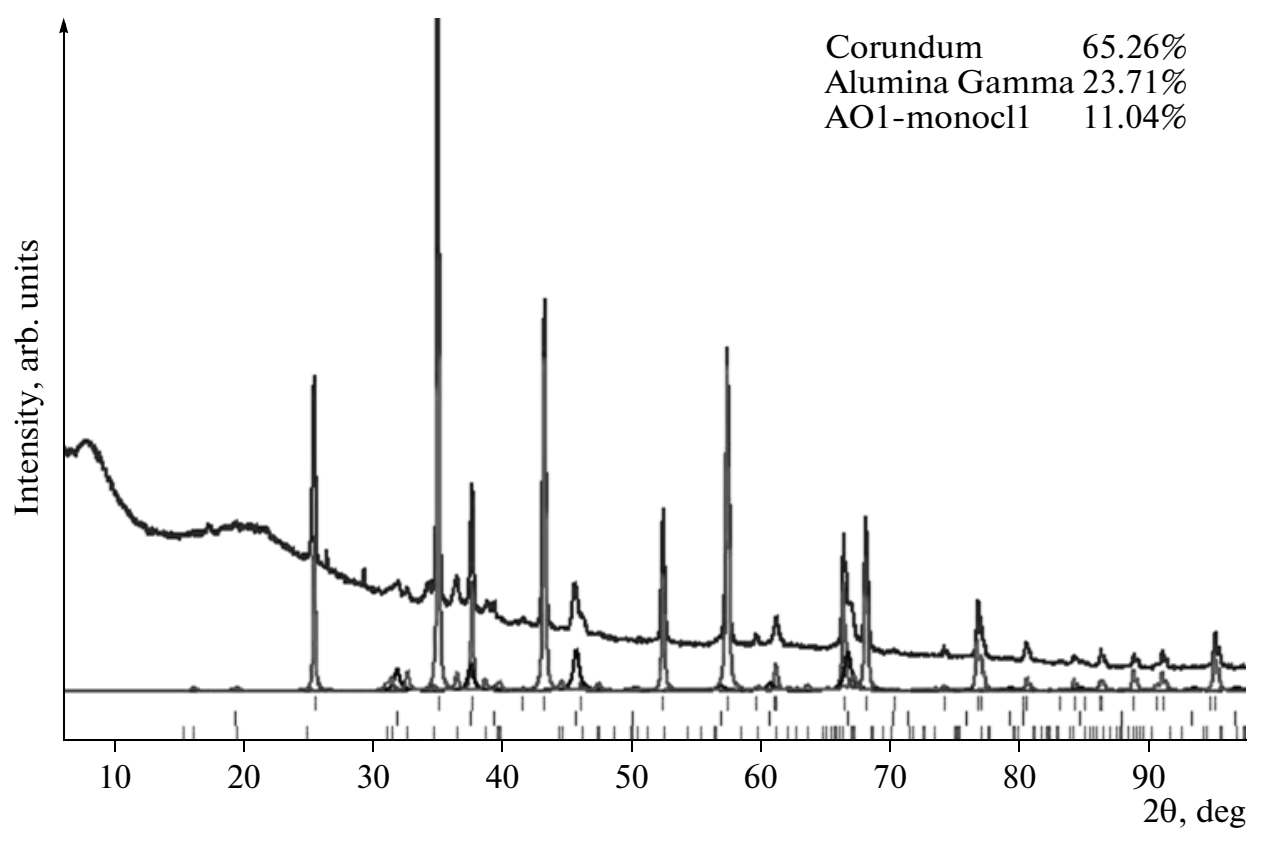

Fig. 1. X-ray diffractogram of the multiphase $\mathrm{Al}_{2} \mathrm{O}_{3} \mathrm{NPW}$.

conditions with different deposition times (5-10 min for coatings and 40-60 min for NPWs) and "targetsubstrate" distances $(5 \mathrm{~cm}$ for coatings and $\approx 10-$ $15 \mathrm{~cm}$ for NPWs). Coatings were deposited onto cover slips $(5 \times 2.4 \mathrm{~cm})$ with a thickness of $0.13-0.18 \mathrm{~mm}$; the deposition of NPWs was conducted on the large surface of a window glass substrate with a thickness of $4 \mathrm{~mm}$ located around the target. Targets-circular disks $60 \mathrm{~mm}$ in diameter and up to $20 \mathrm{~mm}$ in heightwere obtained by annealing in the air at $1000^{\circ} \mathrm{C}$ for $1 \mathrm{~h}$ after pressing (on a manual press) NPWs with a specific surface area $9.8 \mathrm{~m}^{2} / \mathrm{g}$ purchased from IAM (United States). The following diagnostics were used for an investigation into the NPW properties. X-ray diffraction analysis was conducted with XRD 7000 Shimadzu (Japan) and X'PERT PRO (Holland) diffractometers. The specific surface area of powders (S) was determined by BET using Micromeritics TriStar 3000 with a measurement error of $\pm 3 \%$. Heating and cooling thermograms and the mass spectra of the samples were recorded with differential scanning calorimetry (DSC) and thermogravimetry (TG) using an STA-409-PC Luxx synchronous thermoanalyzer coupled with a QMS-403C mass spectrometer (resolution 0.5 amu, Scan, Scan-Bargaph, MiD) from NETZSCH.

The pulsed cathodoluminescence (PCL) was investigated with a KLAVI-1 setup [27]. The coating thickness was determined by weighing the substrate before and after deposition using Sartorius electronic balances (capacity $220 \mathrm{~g}$, readability $0.1 \mathrm{mg}$ ).

\section{RESULTS AND DISCUSSION}

Multiphase $\mathrm{Al}_{2} \mathrm{O}_{3} \mathrm{NPW}$ with a specific surface area up to $270 \mathrm{~m}^{2} / \mathrm{g}$ [2] and amorpous/amorphous-nanocrystal $\mathrm{Al}_{2} \mathrm{O}_{3}$ coatings ( $20-40 \mu \mathrm{m}$ thick) with low adhesion to the glass substrate materials were obtained in the experiments.

It was established that the phase composition of coatings and NPW depended on the deposition time, which indicated the defining role of the duration of thermal treatment of the newly introduced nanoparticles (NPs) on the phase transformations in the layers deposited earlier. The effect of the plasma flame of the evaporated target on the phase composition of NPWs can be excluded because of the large distance between the target and substrates on which the powder was deposited. On the contrary, the thermal effect of the plasma flame on the coatings is not improbable during coating deposition due to the short "target-substrate" distance, which partly resulted in the incontrollable annealing of amorphous coatings formed on NPs hardening on cold surfaces and their partial crystallization.

The diffractogram of the multiphase $\mathrm{Al}_{2} \mathrm{O}_{3} \mathrm{NPW}$ obtained with evaporation by an electron beam in vacuum is presented in Fig. 1.

The $\mathrm{Al}_{2} \mathrm{O}_{3}$ NPW consisted of three crystalline phases: $\alpha-\mathrm{Al}_{2} \mathrm{O}_{3}, \gamma-\mathrm{Al}_{2} \mathrm{O}_{3}, \theta-\mathrm{Al}_{2} \mathrm{O}_{3}$, and an amorphous component. The relative contents of the crystalline phases in the NPW and the average values of coherent scattering regions (CSRs) are presented in Table 1. Narrow and intensive diffraction peaks in Fig. 1 indicate that the prolonged thermal treatment for $40-$ 60 min during the sequential layer deposition of the 
Table 1. Relative content of the crystalline phases and average values of coherent scattering regions $(\mathrm{CSR})$ of the $\mathrm{Al}_{2} \mathrm{O}_{3-\delta} \mathrm{NPW}$

\begin{tabular}{c|c|c|c|c|c|c}
\hline \multirow{2}{*}{ Sample } & \multicolumn{2}{|c|}{$\alpha \mathrm{Al}_{2} \mathrm{O}_{3}$ (corundum) } & \multicolumn{2}{c|}{$\gamma \mathrm{Al}_{2} \mathrm{O}_{3}$ (cubic) } & \multicolumn{2}{c}{$\theta \mathrm{Al}_{2} \mathrm{O}_{3}$ (monoclinic) } \\
\cline { 2 - 7 } & content, mass $\%$ & $\mathrm{CSR}, \mathrm{nm}$ & content, mass $\%$ & CSR, nm & content, mass \% & CSR, nm \\
\hline $\mathrm{Al}_{2} \mathrm{O}_{3-\delta}$ & $65(3)^{*}$ & $78(2)$ & $24(3)$ & $21(2)$ & $11(3)$ & $\approx 30$ \\
\hline
\end{tabular}

* Measurement errors are given in parentheses

NPW on the cold substrate caused the partial crystallization of the amorphous phase of the NPW and resulted in the formation of three polymorphic crystalline phases of $\mathrm{Al}_{2} \mathrm{O}_{3}(\alpha, \gamma$, and $\theta$ phases) in the final product. Notice that the formation of a stable $\mathrm{Al}_{2} \mathrm{O}_{3}$ $\alpha$ phase was not observed previously in NPW obtained with different gas-phase methods (PLD, the electrical explosion of wires, evaporation by a continuous electron beam, chemical vapor deposition, etc.). A moderate fraction of the $\mathrm{Al}_{2} \mathrm{O}_{3} \alpha$ phase (30\%) was found in the multiphase coatings deposited with the plasmadetonation method [28].

Unlike NPW, coatings were either entirely amorphous or with a low content of the crystalline $\gamma$ phase in the amorphous $\mathrm{Al}_{2} \mathrm{O}_{3}$ matrix. Both types of coatings were obtained in experiments with different deposition times (5-10 $\mathrm{min})$ in a noncontrolled manner, which was related with the arbitrary direction of the vapor (plasma flame) on the electron beam scanning the target surface due to the unpredictable shape of the crater and the partial destruction of the target upon evaporation. The preparation of homogenous coatings with equal thicknesses is possible by rotating the target holder and the spiral scanning of the target by the beam, which is planned for the future. Diffractograms of the amorphous and A-NC coatings (before and after annealing in the air at $300^{\circ} \mathrm{C}$ for $1 \mathrm{~h}$ ) obtained with evaporation for 5 min are presented in Fig. 2. Characteristics of the A-NC coatings before and after annealing are given in Table 2.

It can be seen from the diffractogram in Fig. 2a that this coating sample is entirely amorphous (only peaks of diffuse scattering are present without the formation of crystalline phases). The diffractogram of the A-NC coating before annealing (Fig. 2c) is characterized by three narrow peaks with maxima localized at angles $2 \theta \approx 37.76^{\circ}, 45.893^{\circ}$, and $66.9313^{\circ}$. These peaks indicate that a moderate amount of $\gamma$-phase $\mathrm{Al}_{2} \mathrm{O}_{3}$ nanocrystals (NC) with (311), (400), and (440) crystalline orientation are present in the coating composition. The degree of crystallinity of the unannealed sample calculated with the Crystallyty program was $16.6 \%$. It can be seen from Fig. $2 d$ that the new $\gamma$-phase NC with crystalline orientation (222) emerged after the annealing of the coating with the initial $\mathrm{NC}$ with crystalline orientation (311), (400), (440) at $300^{\circ} \mathrm{C}$ for $1 \mathrm{~h}$ and cooling of the sample to room temperature together with the oven. The NC size practically did not change after annealing according to the CSR data (Table 2). The degree of crystallinity of the sample before $(16.6 \%)$ and after $(14.9 \%)$ annealing is close to the experimental error.

Lattice parameters of the $\mathrm{Al}_{2} \mathrm{O}_{3} \gamma$ phase in the A-NC coating before $(7.908 \pm 2 \AA)$ and after $(7.886 \pm 4 \AA)$

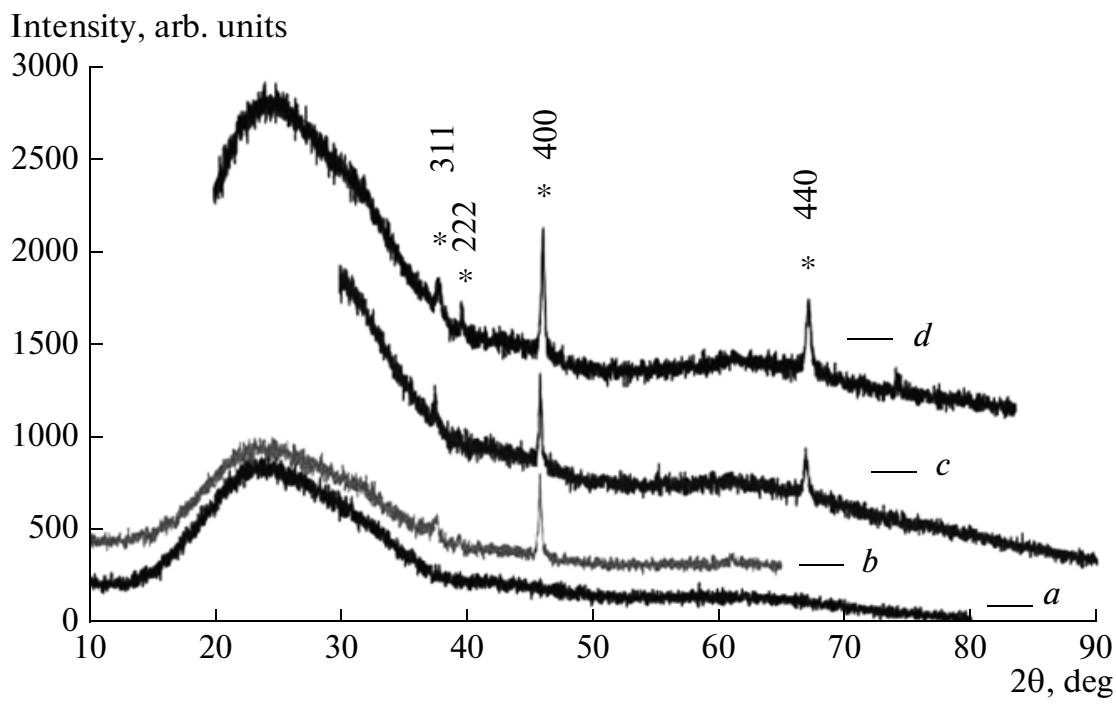

Fig. 2. (a) X-ray diffractogram of the amorphous coating; $(b, c)$ diffractograms of the A-NC coating before annealing at $\theta=10-65^{\circ}$ and $\theta=30-90^{\circ}$; and $(d)$ diffractogram of the A-NC coating after annealing. Miller indexes for the $\gamma-\mathrm{Al}_{2} \mathrm{O}_{3}$ are denoted by $(*)$. 
Table 2. Characteristics of the crystalline $\gamma$ phase of $\mathrm{Al}_{2} \mathrm{O}_{3}$ in the A-NC coating

\begin{tabular}{c|c|c|c|c}
\hline HKL & Line position, degree. & FWHM, degree & $a, \AA$ & CSR size, nm \\
\hline \multicolumn{3}{|c|}{ Before annealing } \\
411 & $37.76 \pm 0.02$ & - & $7.908 \pm 2^{*}$ & \\
440 & $45.893 \pm 0.004$ & $0.22448 \pm 0.016$ & & $81 \pm 8^{*}$ \\
& $66.9313 \pm 0.04$ & $0.44902 \pm 0.04$ & & $30 \pm 3^{*}$ \\
311 & $37.84 \pm 0.04$ & After annealing & \\
222 & $39.48 \pm 0.04$ & - & & \\
400 & $46.081 \pm 0.004$ & $0.29 \pm 0.03$ & & $50 \pm 5^{*}$ \\
440 & $67.110 \pm 0.006$ & $0.46 \pm 0.03$ & & $30 \pm 3^{*}$ \\
\hline
\end{tabular}

* Error is due to the error of the determination of the half width and the position of the line.

annealing are significantly lower than in the standard one (7.924 ̊) [17]. The decrease of the lattice parameter is less in relation to the effect of the size factor, which is known [29] to be more pronounced at the particle size 5-10 $\mathrm{nm}$ (in our case the particles were significantly larger (Table 2)). Most likely the decrease in the lattice parameter is caused by the changes in the $\mathrm{Al}_{2} \mathrm{O}_{3}$ stoichiometry due to the formation of oxygen vacancies and other defects of various types in the coatings. The 400 and 440 lines (Fig. 2) have significantly different widths, confirming high the defectness of the $\mathrm{NC} \mathrm{Al}_{2} \mathrm{O}_{3} \gamma$ phase in the coating.

The CSR calculations were conducted assuming that the line widening is caused only by the small crystallite size. It has not been possible to separate the contributions of the defectiveness and small size of crystallites. The aluminum oxide crystal growth was probably not isotropic and their sizes along $\langle 100\rangle$ and $\langle 110\rangle$ directions differ significantly.

Phase transformations in the multiphase $\mathrm{Al}_{2} \mathrm{O}_{3}$ NPW and A-NC coating upon heating to $1400^{\circ} \mathrm{C}$ differ insignificantly.

The heating and cooling thermograms (DSC-TG) of the multiphase NPW consisting of a mixture of crystalline phases $(\alpha, \gamma$, and $\theta)$ and an amorphous component are presented in Fig. 3.

In the beginning the water adsorbed on the NP surface evaporated (minor endothermic peak up to $\approx 330^{\circ} \mathrm{C}$ ). The intensive exothermic peak of the NPW amporphous phase crystallization follows that. Slow kinetics and the wide temperature range of crystallization (from 330 to $960^{\circ} \mathrm{C}$ ) indicate significant thermal stability of the amorphous phase up to $\approx 960^{\circ} \mathrm{C}$. The large value of the crystallization thermal effect of the amorphous phase indirectly suggests its large content in the NPW.

Note that the process of crystallization of the amorphous phase (exothermic peak) in the multiphase NPW should be accompanied with the parallel competing processes: recrystallization of the initial crystalline phases $(\alpha, \gamma$, and $\theta)$, the growth and crys- tallization of the new $\gamma$-phase crystals, and the evaporation of the chemically bound water (water evaporation from NPW finishes only upon reaching approximately $1300^{\circ} \mathrm{C}$, which is demonstrated by the respective break point on the TG curve). The sharp decline of the TG curve in the temperature range 960$1250^{\circ} \mathrm{C}$ directly indicates the decrease in the hydroscopic $\gamma$ phase in the NPW in the process of the polymorphic transition $\gamma \theta$.

It is most likely that a significant growth in the size of the initial $\alpha$-phase NC and a relatively slow growth of the size of the initial $\gamma$-phase NC occur upon the heating of the multiphase NPW (the latter is confirmed by the XRD data upon the absence of significant growth in the size of $\gamma$-phase NC in A-NC coating after annealing for $1 \mathrm{~h}$ at $300^{\circ} \mathrm{C}$ (Table 2)). The significant decrease in the specific surface area (crystal growth) of the $\alpha$ phase is observed at a sufficiently low temperature above $500^{\circ} \mathrm{C}$ [30]. The higher $\alpha$-phase crystal growth rate is caused by the differences in the surface energies of the polymorphic phases $\left(2.64 \mathrm{~J} / \mathrm{m}^{2}\right.$ for $\alpha$ phase and $1.67 \mathrm{~J} / \mathrm{m}^{2}$ for $\gamma$ phase); therefore, the $\gamma$ phase can retain a high specific surface area $\sim 150 \mathrm{~m}^{2} / \mathrm{g}$ upon heating at the rate $5^{\circ} \mathrm{C} / \mathrm{min}$ to the temperature $900^{\circ} \mathrm{C}$, while the specific surface area of the $\alpha$ phase at this temperature decreases sharply from 156 to $50 \mathrm{~m}^{2} / \mathrm{g}$ [30].

The fraction of the $\gamma$ phase in the initial NPW is relatively small according to the XRD data (Table 1), and the relatively high exothermic peak of the $\gamma \theta$ transition $\left(960-1205^{\circ} \mathrm{C}\right)$ indicates that the largest part of the amorphous phase is crystallized upon heating the NPW to $960^{\circ} \mathrm{C}$. However, it cannot strictly be stated that the entire amorphous component crystallized at $960^{\circ} \mathrm{C}$ considering its high thermal stability [21].

The transformation of the multiphase NPW into the stable $\mathrm{Al}_{2} \mathrm{O}_{3} \alpha$ phase begins from approximately $1205^{\circ} \mathrm{C}$, which is demonstrated with a minor exothermic peak in the temperature range $1080-1400^{\circ} \mathrm{C}$. However, there was probably no final transformation of the multiphase NPW into the stable $\alpha$ phase upon 
(a)

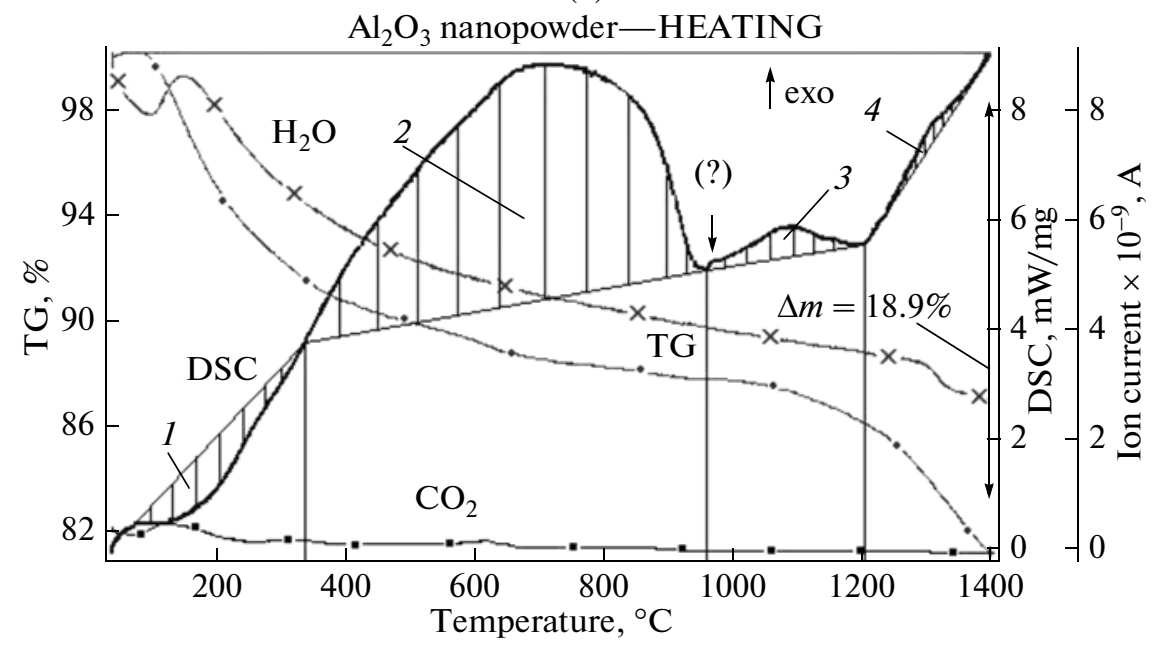

(b)

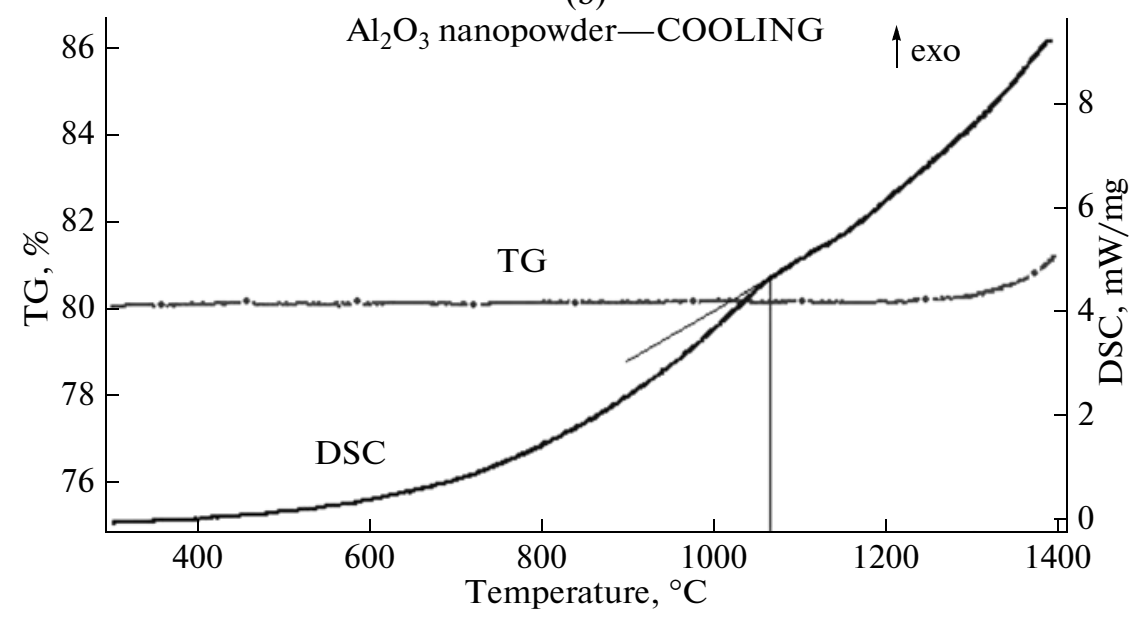

Fig. 3. (a) DSC-TG heating thermograms and $\mathrm{H}_{2} \mathrm{O}$ and $\mathrm{CO}_{2}$ mass spectra of the multiphase $\mathrm{Al}_{2} \mathrm{O}_{3}$ NPW. (The following processes are designated with numbers: (1) evaporation of the adsorbed water, (2) crystallization of the amorphous phase into the $\mathrm{Al}_{2} \mathrm{O}_{3} \gamma$ phase, (3) $\gamma \rightarrow \theta$, (4) $\theta \rightarrow \alpha$ ); (b) DSC-TG cooling thermograms of the multiphase $\mathrm{Al}_{2} \mathrm{O}_{3} \mathrm{NPW}$. The rate of heating and cooling is $10^{\circ} \mathrm{C} / \mathrm{min}$.

heating to $1400^{\circ} \mathrm{C}$, which was evidenced by the availability of the endothermic effect on the DSC cooling curve (Fig. 3b) at around $1065-1070^{\circ} \mathrm{C}$, which indicated the possibility of the reverse transformation of the polymorphic phases according to the $\theta \rightarrow \gamma$ reaction.

The heating and cooling thermogram to $1400^{\circ} \mathrm{C}$ of the A-NC coating, which was picked up from the substrate by the titanium foil following the deposition on the glass, is presented in Fig. 4a. The strong carbonization of the coating should be noted $\left(\mathrm{CO}_{2}\right.$ mass spectrometry curve in Fig. 4a), which is in agreement with the observed strong carbonization (up to 20\%) of the surface layer of plasma-detonation $\mathrm{Al}_{2} \mathrm{O}_{3}$ coatings [28]. Most likely the carbonization of coatings is related to their high porosity and high effective specific surface area of the grains, which results in the adsorption of gas particles from the environment (chemisorption of $\mathrm{CO}_{2}$ on the bridging oxygen atoms with the formation of surface carbonates). The application of the $\gamma-\mathrm{Al}_{2} \mathrm{O}_{3}$ as a carbon sensor is known in practice [35].

Phase transformations in the A-NC coatings proceeded according to the scheme "amorphous phase $\rightarrow$ $\gamma \rightarrow \delta \rightarrow \theta \rightarrow \alpha$." At the beginning, adsorbed water evaporated from the coating (endothermic peak in the temperature range $\approx 50-250^{\circ} \mathrm{C}$ ). The crystallization of the amorphous phase (exothermal peak in the temperature range $250-830^{\circ} \mathrm{C}$ ) began at a lower temperature $\left(250^{\circ} \mathrm{C}\right)$ than in the multiphase $\mathrm{Al}_{2} \mathrm{O}_{3} \mathrm{NPW}$, which is most likely related to the known catalytic effect of water vapor on the crystallization temperature of the amorphous phase [31].

The minor exothermic peak in the temperature range $830-925^{\circ} \mathrm{C}$ is likely related to the polymorphic transformation $\gamma \rightarrow \delta$. Notice that, according to the TG heating curve (Fig. 4a), the water evaporation from the coating finished at the stage of crystallization 
(a)

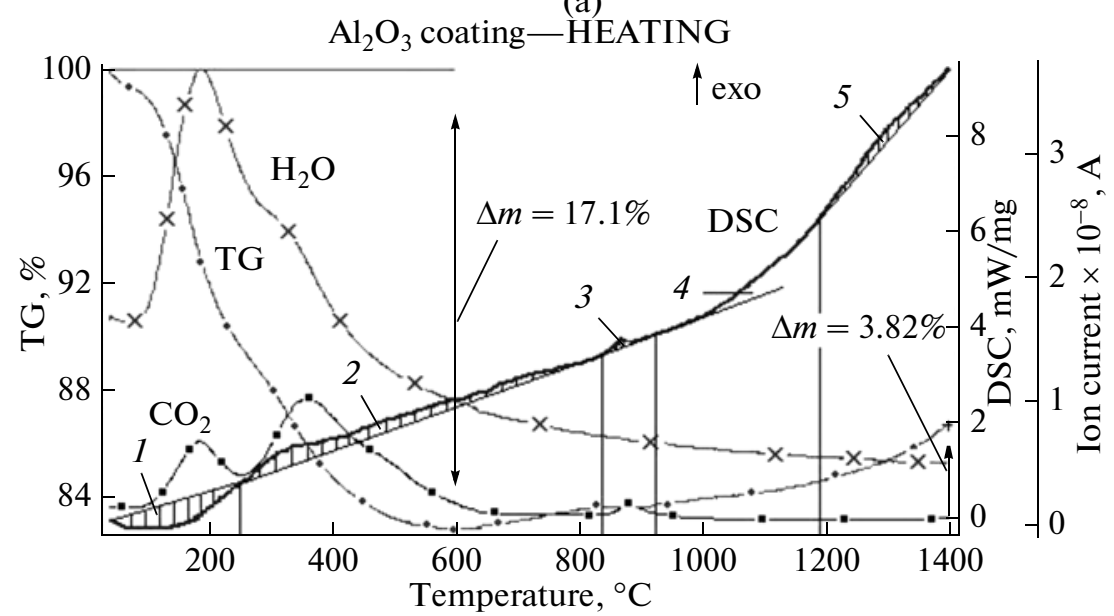

(b)

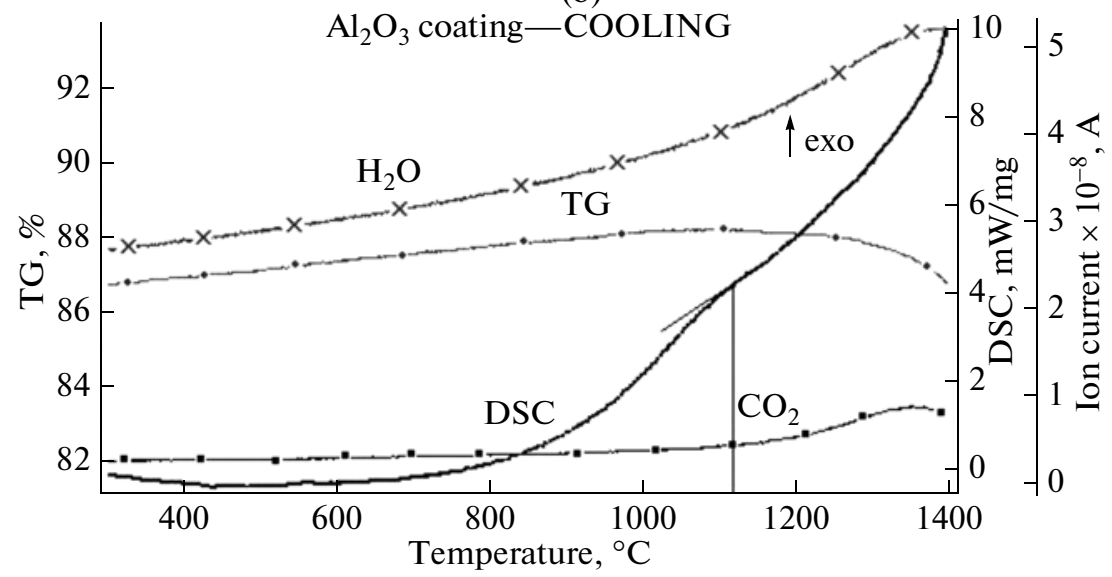

Fig. 4. (a) DSC-TG heating thermograms and $\mathrm{H}_{2} \mathrm{O}$ and $\mathrm{CO}_{2}$ mass spectra of the $\mathrm{A}-\mathrm{NC}_{2} \mathrm{O}_{3}$ coating. (The following processes are designated with numbers: (I) evaporation of the adsorbed water, (2) crystallization of the amorphous phase into the $\mathrm{Al}_{2} \mathrm{O}_{3} \gamma$ phase, (3) $\gamma \rightarrow \delta$, (4) $\delta \rightarrow \theta$, and (5) $\theta \rightarrow \alpha$ ); (b) DSC-TG cooling thermograms and $\mathrm{H}_{2} \mathrm{O}$ and $\mathrm{CO}_{2}$ mass spectra of the A-NC $\mathrm{Al}_{2} \mathrm{O}_{3}$ coating of the multiphase $\mathrm{Al}_{2} \mathrm{O}_{3} \mathrm{NPW}$. The rate of heating and cooling is $10^{\circ} \mathrm{C} / \mathrm{min}$.

of the amorphous phase into the $\gamma$ phase at the lower temperature of approximately $600^{\circ} \mathrm{C}$. The nonmonotonous growth of the mass of the coating was observed, further caused by thermal annealing of oxygen vacancies, a number of which could increase due to the known effect of the increase in porosity of the $\gamma$ phase on heating to the temperatures $400-600^{\circ} \mathrm{C}$, which resulted in the formation of nanosized pores $(2-3 \mathrm{~nm})$ and the respective growth in the number of vacancies in the coating [32].

The thermal effect of the further transformation in the reaction $\delta \rightarrow \theta$ was pronounced much less than in the $\mathrm{Al}_{2} \mathrm{O}_{3} \mathrm{NPW}$. Only the deviation in the exothermic direction of the base line of the DSC curve, most noticeable at approximately $1000^{\circ} \mathrm{C}$, is indicative of the $\delta \rightarrow \theta$ reaction. The minor exothermic peak of the final transformation according to the $\theta \rightarrow \alpha$ reaction was observed starting from around $1080^{\circ} \mathrm{C}$ in the temperature range $1080-1400^{\circ} \mathrm{C}$. The availability of the endothermic effect at approximately $1120^{\circ} \mathrm{C}$ on the cooling curve of the coating (Fig. 4b) also supports the lack of the final transformation of the coating into the stable aluminum $\alpha$ phase upon dynamic heating to $1400^{\circ} \mathrm{C}$ and the possibility of the reverse transformation of the metastable phases in the $\theta \rightarrow \gamma$ reaction upon cooling. However, an investigation into the reversibility of polymorphic phases of $\mathrm{Al}_{2} \mathrm{O}_{3}$ requires the application of high-temperature XRD, which was not among the objectives of this work.

Notice that a very small exothermic peak on the DSC curve of the multiphase $\mathrm{Al}_{2} \mathrm{O}_{3} \mathrm{NPW}$ at $960^{\circ} \mathrm{C}$ (marked with "?" in Fig. 3a) can be caused by the $\gamma \rightarrow \delta$ reaction proceeding with a high rate according to the possible martensite transformation mechanism [33], which is attested to by the narrow temperature range of the transformation $\left(\sim 960-980^{\circ} \mathrm{C}\right)$.

Hence, the data of the DSC-TG analysis of the NPW and coating indicate that the amorphous phase persist in both materials upon their heating at a rate of $10^{\circ} \mathrm{C} / \mathrm{min}$ up to sufficiently high temperatures (830- 


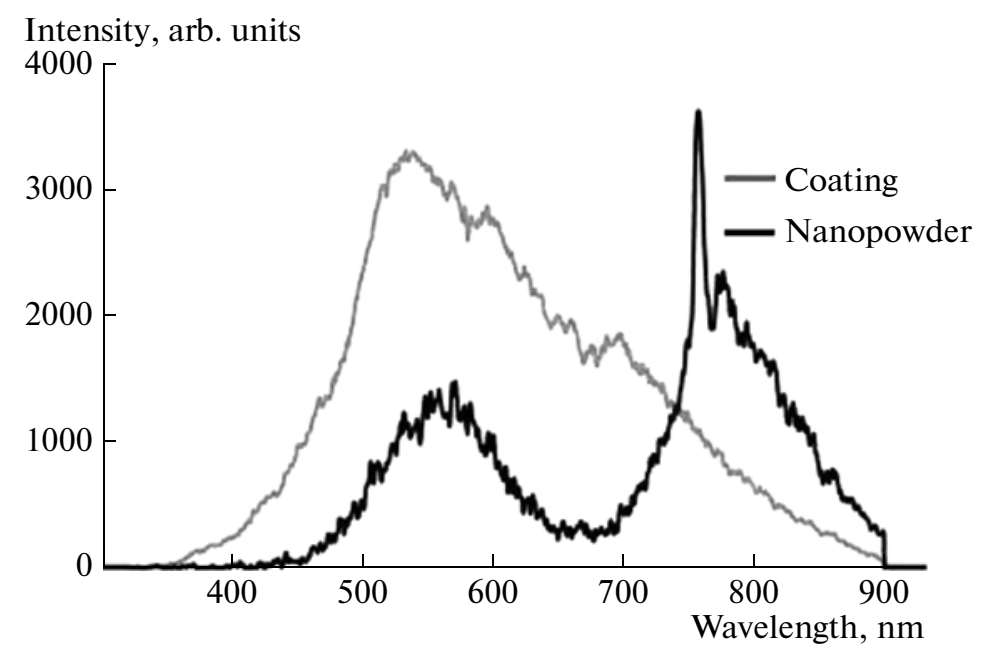

Fig. 5. PCL spectra: A-NC coating and multiphase $\mathrm{Al}_{2} \mathrm{O}$ NPW.

$960^{\circ} \mathrm{C}$ ) and there is no final transformation of the materials into the stable $\alpha$ phase even upon heating to $1400^{\circ} \mathrm{C}$. The amount of oxygen vacancies in the A-NC coating is significantly larger than in the multiphase NPW, which is confirmed by the continuous growth of the mass of the coating (TG curve in Fig. 4a) in the temperature range $600-1400^{\circ} \mathrm{C}$.

Chemically bound water is retained for much longer in the NPW (up to $\approx 1300^{\circ} \mathrm{C}$ ) than in the coating $\left(600^{\circ} \mathrm{C}\right)$, which is preferable for the use of coatings in various low-temperature applications.

The PCL spectra of the multiphase NPW and A-NC coating on the basis of $\mathrm{Al}_{2} \mathrm{O}_{3}$ are presented in Fig. 5. Two wide bands in the green and red regions of the spectrum are observed in the spectrum of the powder sample. The spectrum of the coating comprises a continuous wide band in the visible range wavelengths of $350-900 \mathrm{~nm}$.

The obvious difference in the PCL spectra of the powder and the coating, which were obtained under similar evaporation conditions (with differences only in the time of evaporation and the "target-substrate" distance) confirms their different phase compositions and dependences of the phase formation in coatings and NPW with the pulsed electron-beam evaporation on the deposition time of NPs.

The preliminary studies of the thermo- and optically stimulated luminescence of the multiphase NPW and coatings based on the pure and Fe-doped $\mathrm{Al}_{2} \mathrm{O}_{3}$ conducted in collaboration with researchers from the department of Experimental Physics of the Ural Federal University and the Institute of Industrial Ecology, Ural Branch, Russian Academy of Sciences, showed promising results indicating the possibility of using the abovementioned materials in the dosimetry of various types of ionizing radiation [34].

\section{CONCLUSIONS}

Coatings and multiphase NPWs based on $\mathrm{Al}_{2} \mathrm{O}_{3}$ were obtained with pulsed electron-beam evaporation in vacuum. The phase composition of the coatings and NPW depends primarily on the deposition time of NPs. The formation of the amorphous phase and various polymorphic phases of the $\mathrm{Al}_{2} \mathrm{O}_{3}$ occurred in both types of materials. The $\alpha$ and $\theta$ phases of $\mathrm{Al}_{2} \mathrm{O}_{3}$ were found in the composition of NPW, which is not typical for gas-phase methods. Both purely amorphous and A-NC coatings containing minor fractions of the crystalline $\gamma$ phase were obtained. The specific surface area of the multiphase $\mathrm{Al}_{2} \mathrm{O}_{3} \mathrm{NPW}$ reached $270 \mathrm{~m}^{2} / \mathrm{g}$. The minimum average size of the CSR of the $\gamma$ phase in NPWs and coatings was 21 and $40 \mathrm{~nm}$, respectively. The routes of phase transformations in the NPW and coatings upon dynamic heating to $1400^{\circ} \mathrm{C}$ were investigated with the DSC-TG method. The number of oxygen vacancies in the A-NC coating is significantly higher than in the multiphase NPW.

The cathodoluminescence of the NPW is characterized with the presence of two wide bands with maximums at $495-510$ and $695.6 \mathrm{~nm}$. The PCL spectrum of the coatings is presented as a wide spectral band in the wavelength range $350-900 \mathrm{~nm}$. The significant difference in the PCL spectra of the powder and coatings is caused by their different phase composition.

Luminescent characteristics of the coatings and NPW and the relatively high thermal stability (830$960^{\circ} \mathrm{C}$ ) of the crystalline $\gamma$ phase forming as a result of the crystallization of the amorphous component of the materials offer promise for use in the dosimetry of ionizing radiation, optoelectronics, and other applications. 


\section{ACKNOWLEDGMENTS}

We are grateful to S.V. Pryanichnikov, Cand. Sci. (Phys.-Math.), Institute of Metallurgy, Ural Branch, Russian Academy of Sciences, for the XRD of the coatings, and to the following researchers at the Institute of Electrophysics, Ural Branch, Russian Academy of Sciences: A.V. Spirina, Cand. Sci. (Phys.Math.), for recoding of PCL spectra; T.M. Demina, Junior Scientific Researcher, for measurements of the specific surface area and recording DSC-TG thermograms of the powder and coatings; and A.I. Medvedev, Cand. Sci. (Phys.-Math.), for the XRD of the nanopowder.

This study was supported by the Ministry of Education and Science of the Russian Federation, state contract no. 14.740.11.0834.

\section{REFERENCES}

1. A. Sundaresan, R. Bhargavi, N. Rangarajan, U. Siddesh, and C. N. R. Rao, "Ferromagnetism as a universal feature of nanoparticles of the otherwise nonmagnetic oxides," Phys. Rev. B: Condens. Matter Mater. Phys. 74 (16), 161306 (6) (2006).

2. V. G. Il'ves, A. I. Medvedev, A. M. Murzakaev, S. Yu. Sokovnin, A. V. Spirina, and M. A. Uimin, "Physical characteristics of $\mathrm{Al}_{2} \mathrm{O}_{3}-\mathrm{Al}(\mathrm{Cu})$ nanopowders synthesized by means of electron beam evaporating of target," Fiz. Khim. Obrab. Mater., No. 2, 65-70 (2011).

3. Y. L. Zheng, C. M. Zhen, X. Q. Wang, X. L. Li, and D. L. Hou, "Room-temperature ferromagnetismobserved in alumina films," Solid State Sci. 13 (8), 15161519 (2011).

4. P. Eklund, M. Sridharan, G. Singh, and J. Bottiger, "Thermal stability and phase transformations of $\gamma$-/amorphous- $\mathrm{Al}_{2} \mathrm{O}_{3}$," Thin Films Plasma Processes Polym. 6 (S1), S907-S911 (2009).

5. X. F. Duan, N. H. Tran, N. K. Roberts, and R. N. Lamb, "Solvothermal approach for low temperature deposition of aluminium oxide thin films," Thin Solid Films 518 (15), 4290-4293 (2010).

6. V. Edlmayr, M. Moser, C. Walter, and C. Mitterer, "Thermal stability of sputtered $\mathrm{Al}_{2} \mathrm{O}_{3}$ coatings," Surf. Coat. Techn. 204, 1576-1581 (2010).

7. T. Kohara, H. Tamagaki, Y. Ikari, and H. Fujii, "Deposition of a- $\mathrm{Al}_{2} \mathrm{O}_{3}$ hard coatings by reactive magnetron sputtering," Surf. Coat. Techn. 185, 166-171 (2004).

8. R. Romàn, T. Hernàndez, and M. Gonzàlez, "Nano or micro grained alumina powder? A choose before sintering," Boletín de la Sociedad Española de Cerámica y Vidrio 47 (6), 311-318 (2008).

9. G. R. Karagedov and A. L. Myz, "Preparation and sintering pure nanocrystalline $\gamma$-alumina powder," J. Europ. Ceramic Soc. 32 (1), 219 (2012).

10. K. Yatsui, T. Yukawa, C. Grigoriu, M. Hirai, and W. Jiang, "Synthesis of ultrafine $\gamma-\mathrm{Al}_{2} \mathrm{O}_{3}$ powders by pulsed laser ablation," J. Nanopart. Res. 2 (1), 75-83 (2000).

11. D. A. Dubov, Vl. Snytnikov, and V. N. Snytnikov, "The way to produce nanopowders of hard-melting oxides by means of laser evaporation," in Collection of Novosibirsk State Technical University Scientific Works (Novosibirsk State Technical University, 2005), Vol. 42, No. 4, pp. 83-90.

12. S. P. Bardakhanov, A. I. Korchagin, N. K. Kuksanov, A. V. Lavrukhin, R. A. Salimov, S. N. Fadeev, and V. V. Cherepkov, "Use of an electron accelerator to produce nanopowders by evaporation of initial materials at atmospheric pressure,” Russ. Phys. J. 50 (2), 120-124 (2007).

13. S. Schlabach, V. Szabó, D. Vollath, A. Braun, and R. Clasen, "Structure of alumina and zirconia nanoparticles synthesized by the Karlsruhe Microwave Plasma Process," Solid State Phenom. 99-100, 191196 (2004).

14. K. Jiang, K. Sarakinos, S. Konstantinidis, and J. M. Schneider, "Low temperature synthesis of $\alpha-\mathrm{Al}_{2} \mathrm{O}_{3}$ films by high-power plasma-assisted chemical vapour deposition," J. Phys. D: Appl. Phys. 43, 325202(15) (2010).

15. D. L. Alontseva, S. N. Bratushka, A. D. Pogrebnyak, N. V. Prokhorenkova, and V. T. Shablya, "Structure and properties of coatings and modified layers, produced by with the help of plasma fluxes," Fiz. Inzh. Poverkhn. 5 (3-4), 124-139 (2007).

16. A. D. Pogrebnyak, M. I. Il'yashenko, S. N. Bratushka, V. V. Ponaryadov, and N. K. Erdybaeva, "The way to form high-dispersed state in plasma-detonating coating made of aluminium oxide," Fiz. Inzh. Poverkhn. 4 (1-2), 32-47 (2006).

17. I. Levin and D. Brandon, "Metastable alumina polymorphs: crystal structures and transition sequences," J. Amer. Ceram. Soc. 81 (8), 1995-2012 (1998).

18. L. A. Krushinskaya and Ya. A. Stel'makh, "Structure and some properties of thick aluminium-oxide condensates produced by electron-beam evaporation and deposition of vapor phase in vacuum," VANT. Ser.: Chist. Mater. Vac. Technol. 19 (6), 92-98 (2011).

19. E. Krumov, V. Mankov, and K. Starbova, "Nanosized columnar microstructure and related properties of electron gun deposited $\mathrm{Al}_{2} \mathrm{O}_{3}$ thin films," Vacuum 76, 211214 (2004).

20. H. H. Huang, Y. S. Liu, Y. M. Chen, M. C. Huang, and M. C. Wang, "Effect of oxygen pressure on the microstructure and properties of the $\mathrm{Al}_{2} \mathrm{O}_{3}-\mathrm{SiO}_{2}$ thin films deposited by E-beam evaporation," Surf. Coat. Techn. 200, 3309-3313 (2006).

21. N. Yu, T. W. Simpson, P. C. McIntyre, M. Nastasi, and I. V. Mitchell, "Doping effects on the kinetics of solid phase epitaxial growth of amorphous alumina thin films on sapphire," Appl. Phys. Lett. 67, 924-926 (1995).

22. V. S. Kortov, I. I. Mil'man, and S. V. Nikiforov, "Solid dosimetry,” Izv. Tomsk. Politekhn. Univ. 303 (2), 35-45 (2000). 
23. J. E. Villarreal-Barajas, L. Escobar-Alarcón, E. Camps, P. R. González, E. Villagrán, and M. Barboza-Flores, "Thermoluminescence response of aluminum oxide thin films to beta-particle and UV radiation" Superficies y Vacio 13, 126-129 (2001).

24. A. Arrieta, L. Escobar-Alarcón, E. Camps, and P. R. González, "Thermoluminescent response of aluminium oxide thin films subject to gamma irradiation," Radiat. Effects Defects Solids: Incorporating Plasma Sci. Plasma Techn. 162 (10-11), 745-749 (2007).

25. S. K. Menta and S. Sengupta, "Gamma dosimetry with $\mathrm{Al}_{2} \mathrm{O}_{3}$ thermoluminiscent phosphor," Phys. Med. Biol. 21 (96), 955-864 (1976).

26. Yu. A. Kotov, S. Yu. Sokovnin, V. G. Il'ves, and C. K. Rhee, RF Patent No. 2353573, B82B 3/00, Byull. Izobret., No. 12 (2009).

27. S. G. Mikhailov, V. V. Osipov, and V. I. Solomonov, "Pulse cathodoluminescent analyzer KLAVI 1 AU," Prib. Tekhn. Eksperim., No. 3, 164-165 (2001).

28. A. D. Pogrebnyak, Yu. N. Tyurin, Yu. F. Ivanov, A. P. Kobzev, O. P. Kul'ment'eva, and M. V. Il'yashenko, "The way to produce and research the structure and properties of plasma-detonation coatings made of $\mathrm{Al}_{2} \mathrm{O}_{3}$," Pis'ma Zh. Tekh. Fiz. 26 (21), 3-60 (2000).

29. A. I. Gusev and A. A. Rempel', Nanocrystalline Materials (Fizmatlit, Moscow, 2000) [in Russian].
30. J. M. McHale, A. Auroux, A. J. Perrotta, and A. Navrotsky, "Surface energies and thermodynamic phase stability in nanocrystalline aluminas," Science 277, 788-791 (1997).

31. Z. Zhou, H. Guo, M. Abbas, and S. Gong, "Effect of water vapor on the phase transformation of alumina grown on NiAl at 950 C," Corrosion Sci. 53, 29432947 (2011).

32. R. Nakamura, T. Shudo, A. Hirata, M. Ishimaruand, and H. Nakajima, "Nanovoid formation through the annealing of amorphous $\mathrm{Al}_{2} \mathrm{O}_{3}$ and $\mathrm{WO}_{3}$ films," Scripta Mater. 64, 197-200 (2011).

33. V. V. Storozh, G. Ya. Yakimov, I. V. Gorelik, and N. G. Labinskaya, "The way to research polymorphous transitions in aluminium oxide. I. Experiment," Zh. Tekh. Fiz. 66 (9), 86-97 (1996).

34. A. I. Surdo, I. I. Milman, V. G. Il'ves, and S. Yu. Sokovnin, OSL and TL of Nanostructured Aluminum Oxide Thin Layers (in press).

35. T. Okabayashi, T. Fujimoto, I. Yamamoto, K. Utsunomiya, T. Wada, Y. Yamashita, N. Yamashita, and M. Nakagawa, "High sensitive hydrocarbon gas sensor utilizing cataluminescence of gamma- $\mathrm{Al}_{2} \mathrm{O}_{3}$ activated by $\mathrm{Dy}^{3+}$," Sens. Actuators B 64, 54-58 (2000).

Translated by L. Brovko 